UCRL-ID-130063

\title{
Stress Corrosion Cracking in Canistered Waste Package Containers: Welds and Base Metals
}

\author{
Jia-Song Huang
}

March 1998

This is an informal report intended primarily for internal or limited external distribution. The opinions and conclusions stated are those of the author and may or may not be those of the Laboratory.

Work performed under the auspices of the U.S. Department of Energy by the Lawrence Livermore National Laboratory under Contract W-7405-Eng-48. 


\section{DISCLAIMER}

This document was prepared as an account of work sponsored by an agency of the United States Government. Neither the United States Government nor the University of California nor any of their employees, makes any warranty, express or implied, or assumes any legal liability or responsibility for the accuracy, completeness, or usefulness of any information, apparatus, product, or process disclosed, or represents that its use would not infringe privately owned rights. Reference herein to any specific commercial product, process, or service by trade name, trademark, manufacturer, or otherwise, does not necessarily constitute or imply its endorsement, recommendation, or favoring by the United States Government or the University of California. The views and opinions of authors expressed herein do not necessarily state or reflect those of the United States Government or the University of California, and shall not be used for advertising or product endorsement purposes.

This report has been reproduced directly from the best available copy.

Available to DOE and DOE contractors from the Office of Scientific and Technical Information

P.O. Box 62, Oak Ridge, TN 37831

Prices available from (615) 576-8401, FTS 626-8401

Available to the public from the

National Technical Information Service

U.S. Department of Commerce

5285 Port Royal Rd.,

Springfield, VA 22161 


\title{
Stress Corrosion Cracking in Canistered Waste Package Containers: Welds and Base Metals
}

\author{
Jia-Song Huang
}

\section{Introduction}

The current design of waste package containers include outer barrier using corrosion allowable material (CAM) such as A516 carbon steel and inner barrier of corrosion resistant material (CRM) such as alloy 625 and C22. There is concern whether stress corrosion cracking would occur at welds or base metals. The current memo documents the results of our analysis on this topic.

\section{The methodology of stress corrosion cracking analysis}

For stress corrosion cracking(SCC) to occur three factors have to exist: stress, crack, and material-specific corrosive environment. Cracks can either pre-exist due to poor manufacturing practices or be initiated at locations where high stress concentration exists, such as at a groove or corrosion pit. Stress can exist due to welding residual stress, shrink-fit stress, or weight stress. Fracture mechanics is by far the best approach to assess the tendency for stress corrosion cracking to occur. Once a crack is initiated, the crack will grow by SCC when the applied stress intensity factor, $\mathrm{K}$, is equal or larger than stress corrosion cracking resistance parameter, $\mathrm{K}_{\mathrm{ISCC}} \cdot \mathrm{K}_{\mathrm{ISCC}}$ is a material and environment dependent property which can be obtained through fracture mechanics testing of the materials in the specified environment. $\mathrm{K}$ can be calculated through the fracture mechanics formula such as the following:

$$
\mathrm{K}=\beta \sigma(\pi \mathrm{a})^{1 / 2}
$$

where $\beta$ is a geometry factor dependent on the shape of the crack. For a surface elliptical crack with depth, a, and length of $2 c$, under tensile loading, $\beta$ depends upon the aspect ratio of the crack, a/2c, the ratio of crack depth over the thickness of the structure, and the ratio of crack depth over the width of the structure. The solutions for $\beta$ are readily available in typical fracture mechanics textbooks such as reference [1], and will not be duplicated here.

Equation 1 applies only to an ideal crack. For a corrosion pit, a small crack has to be first initiated at the base of the pit before it can grow by SCC. A crack can be initiated in several ways such as over-load induced tearing, grain boundary sensitization, or breakage of near-by inclusion. To determine when a small crack will be initiated is a difficult task. In our analysis we assumed that a crack fissure with the length of $\delta$ a was readily developed along the base of the pit on the plane normal to the applied stress direction. It was assumed .that, $\delta a=$ one grain size $=40 \mu \mathrm{m}(.0015 \mathrm{inch})$. Under this situation the criteria for this crack to continue to grow by SCC can be expressed by the following formula,

$$
\mathrm{K}=\alpha \beta \sigma\left(\pi\left(\mathrm{a}_{\mathrm{pit}}+\delta \mathrm{a}\right)\right)^{1 / 2}
$$


where, $a_{\mathrm{pit}}$ is the depth of the pit, $\beta$ is a geometry factor dependent on the depth of the pit and the aspect ratio as described in equation $1, \alpha$ is another geometry factor accounting for the effect that the pit including the crack fissure is not an ideal crack. The solution for $\alpha$ has been derived by Newman ${ }^{2}$ in graphic form and is given in reference 2 .

It should be noted that for the asymptotic situation where the crack fissure size is much less than the depth of the corrosion pit, i.e., $\delta a \ll a_{\text {pit }}$, the applied stress intensity factor, $\mathrm{K}$ can be expressed as,

$$
\mathrm{K}=\beta \cdot \mathrm{K}_{\mathrm{t}} \cdot \sigma(\delta \mathrm{a})^{1 / 2}
$$

$\mathrm{K}_{\mathrm{t}}$ is the elastic stress concentration factor at the tip of the pit and is calculated as,

$$
\mathrm{K}_{\mathrm{t}}=1+2 \cdot \mathrm{a} / \mathrm{c}
$$

and $\mathrm{a}$ and $2 \mathrm{c}$ are the depth and diameter of the elliptical-shape pit.

\section{Stress in the waste package containers}

\section{a. Weight stress}

In the basc metals of containers, the only stresses which exist are the weight stress and shrink-fit stress. The weight stress can be calculated by the elasticity theory of beam given as,

$$
\sigma=\mathrm{Mr} / \mathrm{I}
$$

where the stress, $\sigma$, is along the longitudinal direction of the container, $r$ is the distance of any location of interest away from the center-axis of the container. $I$ is the moment of the inertia of the cross section of the container, given as

$$
\mathrm{I}=\pi / 4 \cdot\left(\mathrm{r}_{0} 4-\mathrm{r}_{\mathrm{i}} 4\right)
$$

$r_{0}$ and $r_{i}$ are the outer and inner of the radius of the cylinder container. For the analysis of outer barrier, $\mathrm{r}_{0}$ is taken as $0.825 \mathrm{~m}$ (32.48 inch), and $\mathrm{r}_{\mathrm{i}}$ is taken as $0.725 \mathrm{~m}$ (28.54 inch). For the analysis of the inner barrier, $r_{0}$ is taken as $0.725 \mathrm{~m}\left(28.54\right.$ inch) and $r_{i}$ is taken as $0.705 \mathrm{~m}(27.75 \mathrm{inch})$.

$M$ in equation 5 is given by the following formula,

$$
\mathrm{M}=1 / 8 \mathrm{pL}^{2}
$$

where $L$ is the length of the container between base supports of the container. $p$ is the uniformly-distributed weight along the length of the container. In our analysis, $\mathrm{L}$ is taken

- as the half of the total container length, i.e., $\mathrm{L}=2.67 \mathrm{~m}$. The weight of the package, W, is taken as $50423 \mathrm{~kg}$, and $\mathrm{p}$ is calculated as $\mathrm{W} /(2 \mathrm{~L})$.

Based on the above equations, the maximum weight stresses calculated for A516/625 and A516/C22 container systems, are $0.46 \mathrm{MPa}$ in the carbon steel and $2.6 \mathrm{MPa}$ in the 625 and C22 alloy. 


\section{b. Shrink-fit stress}

In the shrink fitting of two cylinders, the shrink-fit stress (in tangential direction) at the outer surface of the outer cylinder (carbon steel) can be calculated as ${ }^{3}$,

$$
\sigma_{\mathrm{o}}=2\left[\mathrm{p} \mathrm{R} \mathrm{R}^{2} /\left(\mathrm{r}_{\mathrm{o}}^{2}-\mathrm{R}^{2}\right)\right]
$$

and the maximum stress (in tangential direction) in the inner cylinder (625 or C22 alloy) is at the interface, $r=R$, and can be calculated $\mathrm{as}^{3}$,

$$
\sigma_{i}=p\left(R^{2}+r_{i}^{2}\right) /\left(R^{2}-r_{i}^{2}\right)
$$

where $r_{o}$ is the outer radius of the outer container, taken as $0.825 \mathrm{~m}, \mathrm{R}$ is the inner radius of the outer container, taken as $0.725 \mathrm{~m}, \mathrm{r}_{\mathrm{i}}$ is the inner radius of the inner container, taken as $0.705 \mathrm{~m}$, and $\mathrm{p}$ is the contact pressure on the interface due to the slight over-size of the outer radius of the inner cylinder over the inner radius of the outer cylinder. This oversize, $\delta$, is called radial interference and is assumed as $0.89 \mathrm{~mm}(0.035$ inch). The contact pressure can be calculated as the following ${ }^{3}$,

$$
\mathrm{p}=\mathrm{E} \delta / \mathrm{R} \cdot\left[\left(\mathrm{r}_{\mathrm{o}}^{2}-\mathrm{R}^{2}\right)\left(\mathrm{R}^{2}-\mathrm{r}_{\mathrm{i}}^{2}\right) / 2 \mathrm{R}^{2}\left(\mathrm{r}_{0}^{2}-\mathrm{r}_{\mathrm{i}}^{2}\right)\right]
$$

where $\mathrm{E}$ is the elastic modulus of both the inner and outer cylinders, taken as $207000 \mathrm{MPa}$ (30000 ksi).

Based on the above equations, $\mathrm{p}$ was calculated as $5.85 \mathrm{MPa}(847.5 \mathrm{psi})$, the shrink-fit stress at the outer surface of the outer cylinder was calculated as $40 \mathrm{Mpa}$ ( $5742 \mathrm{psi}$ ), and the maximum shrink-fit stress for the inner cylinder was calculated as -207 MPa (30199 psi), which is a compressive stress. However it should be noted that, as the outer barrier carbon steel is eventually corroded away, the shrink-fit stress will be zero in the inner barrier. Therefore the shrink fit stress in the inner container will be taken as zero in our analysis.

\section{c. Welding residual stress}

In the welds, the welding residual stress has to be considered. In the fabrication of the waste package containers, the welds will be mostly stress relieved except the final closure weld which has not been specified to be relieved. The welding residual stress in this case can be as high as the yield strength of the material. The yield strength is $205 \mathrm{MPa}$ for A516 Gr.55 carbon steel; $407 \mathrm{MPa}$ for $\mathrm{C} 22$ alloy; and $483 \mathrm{MPa}$ for Alloy 625. In summary, the stresses on waste package containers are shown in the following table,

Table 1 Stress $(\mathrm{MPa})$ in the waste package container

Weight stress, $\quad$ Shrink-fit stress $\quad \begin{gathered}\text { Max. weld } \\ \text { residual stress }\end{gathered} \begin{gathered}\text { Max. total } \\ \text { stress }\end{gathered}$

$\begin{array}{lcccc}\text { A516, Gr. 55 } & 0.46 & 40 & 205 & 245 \\ \text { C22 } & 2.6 & 0 & 407 & 409.6 \\ 625 & 2.6 & 0 & 483 & 485.6\end{array}$




\section{Stress corrosion cracking resistance, $\mathbf{K}_{\mathrm{ISCC}}$}

Ajit Roy ${ }^{4}$ has conducted fracture mechanics SCC testing on C22 and alloy 625. The minimum $\mathrm{K}_{\text {ISCC }}$ he obtained is $30 \mathrm{MPa}-\mathrm{m}^{1 / 2}$ for $\mathrm{C} 22$ alloy, and $33 \mathrm{MPa}-\mathrm{m}^{1 / 2}$ for 625 alloy. These values will be used in our following analysis to determine whether SCC will occur in corrosion pits developed in these alloys.

For carbon steel, a correlation between $\mathrm{K}_{\mathrm{ISCC}}$ and Vicker hardness has been reported for $3.5 \% \mathrm{NaCl}$ solution as shown in Fig. $1^{5}$. The Vicker hardness for A516 Gr. 55 carbon steel is typically 120 , therefore the $\mathrm{K}_{\mathrm{ISCC}}$ of this carbon steel was estimated as $71 \mathrm{MPa}-\mathrm{m}^{1 / 2}$.

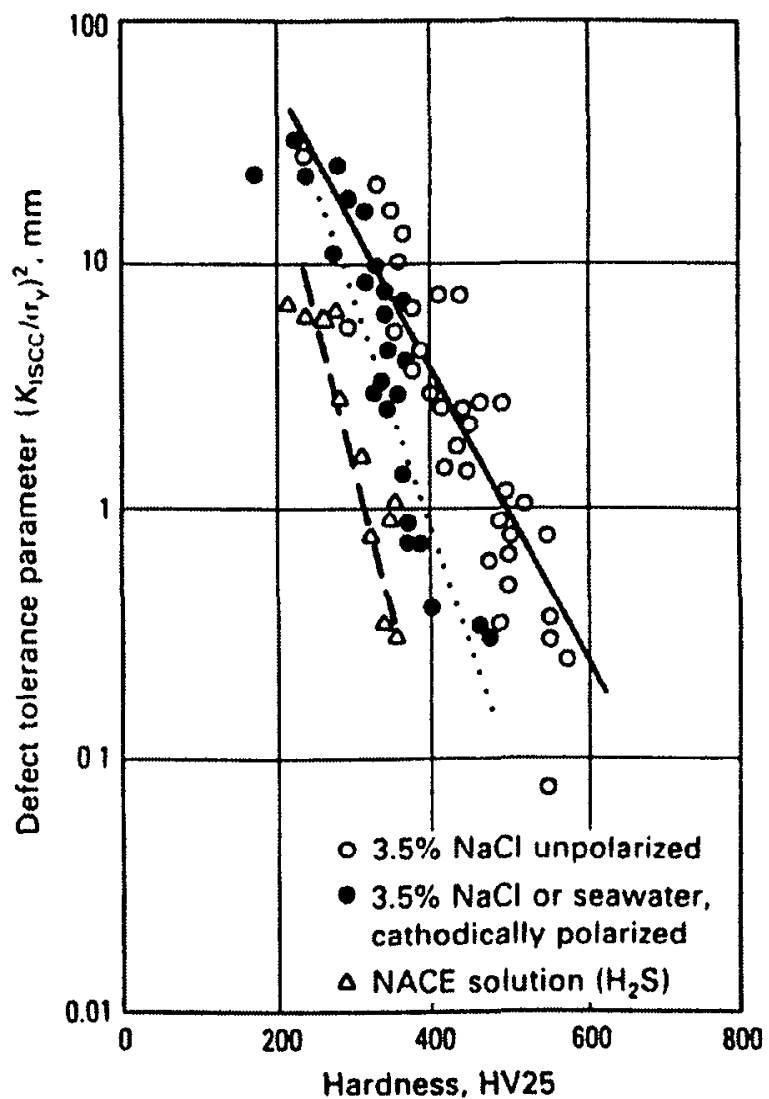

Fig. 1 Stress-corrosion cracking defect tolerance parameter vs. hardness for carbon steel weldments.

\section{Stress corrosion cracking analysis and discussion}

Corrosion pits can be developed at welds and base metals of waste package containers after long exposure to the environment. These act as stress risers to initiate crack fissures at the bases of the pits. SCC can be initiated from these pits when the applied stress intensity factors on these pits are equal or larger than $\mathrm{K}_{\mathrm{ISCC}}$ of the materials. Using the

- solution for $\mathrm{K}$ in equation 2 and the $\mathrm{K}_{\mathrm{ISCC}}$ data given in the last section, the critical size of pit for stress corrosion cracking initiation, defined as when $\mathrm{K}=\mathrm{K}_{\mathrm{ISCC}}$, was calculated and given in Table 2 as a function of pit aspect ratio $(\mathrm{a} / 2 \mathrm{c})$ at different stress levels. Note that, except for the very high aspect ratio $(\mathrm{a} / 2 \mathrm{c}=5)$, the critical size for $\mathrm{SCC}$ is always larger than the thickness of the barriers in the range of stress and aspect ratio considered. In the base metals, since the expected stress will be much lower (see Table 1) than the stress range studied here, we can conclude that there will be no SCC in base metals. 
In the welds, even though the stress can be very high due to the presence of residual stress, the aspect ratio of corrosion pits seldom exceeds 1 as indicated from the limited data by Henshall and Roy ${ }^{6}$ which show that the aspect ratio of corrosion pit in Incoloy 825 (in $5 \% \mathrm{NaCl}$ solution, $\mathrm{PH}=2.57, \mathrm{~T}=90^{\circ} \mathrm{C}$ ) scldom exceeds 1 . The results in Table 2 then suggest that SCC will not occur in welds, even when they are not stress-relieved.

However it should be noted that the current analysis is based on liner elastic fracture mechanics. When the stress applied on a crack or corrosion pit is close to or beyond yield stress, there is a possibility that the linear elastic fracture overestimates the critical defect size for SCC. Under this situation, elastic-plastic fracture mechanics bascd on the Jintegral approach ${ }^{1}$ needs to be used. In order to use this elastic-plastic fracture mechanics approach, accurate stress-strain curve of material is needed to characterize its strainhardening behavior. We will continue to obtain these data and conduct elastic-plastic fracture mechanics analysis in the future. In the interim stage we recommend that the maximum stress on the welds were relieved to less than 0.75 yield strength of the materials.

Table 2 Critical size (mm) of corrosion pit for initiation of stress corrosion cracking. (Yield strength $=205 \mathrm{MPa}$ for A516 Gr.55; $=483 \mathrm{MPa}$ for alloy $625 ;=407$ $\mathrm{MPa}$ for $\mathrm{C} 22$. Note: Critical size $>\mathrm{t}$ means $\mathrm{SCC}$ can not be initiated.)

$$
\underline{\mathrm{a} / 2 \mathrm{c}=0.25} \quad \underline{\mathrm{a} / 2 \mathrm{c}=0.5} \quad \underline{\mathrm{a} / 2 \mathrm{c}=1} \quad \underline{\mathrm{a} / 2 \mathrm{c}=2} \quad \underline{\mathrm{a} / 2 \mathrm{c}=5}
$$

\begin{tabular}{|c|c|c|c|c|c|}
\hline \multicolumn{6}{|c|}{ A516 Gr. 55, $t=100 \mathrm{mr}$} \\
\hline $245 \mathrm{MPa}$ & $>\mathrm{t}$ & $>t$ & $>\mathrm{t}$ & $>t$ & $>t$ \\
\hline $153.8 \mathrm{MPa}$ & $>t$ & $>t$ & $>t$ & $>t$ & $>t$ \\
\hline $102.5 \mathrm{MPa}$ & $>t$ & $>t$ & $>t$ & $>\mathrm{t}$ & $>t$ \\
\hline \multicolumn{6}{|c|}{$($ Alloy $625, t=20 \mathrm{~mm})$} \\
\hline $485.6 \mathrm{MPa}$ & $>t$ & $>t$ & $>t$ & $>t$ & 12 \\
\hline $362.3 \mathrm{MPa}$ & $>t$ & $>t$ & $>t$ & $>\mathrm{t}$ & $>t$ \\
\hline $241.5 \mathrm{MPa}$ & $>t$ & $>t$ & $>t$ & $>t$ & $>t$ \\
\hline \multicolumn{6}{|c|}{$(\mathrm{C} 22, \mathrm{t}=20 \mathrm{~mm}))$} \\
\hline $409.6 \mathrm{MPa}$ & $>t$ & $>\mathrm{t}$ & $>t$ & $>t$ & 14 \\
\hline $305.3 \mathrm{MPa}$ & $>t$ & $>t$ & $>t$ & $>t$ & $>t$ \\
\hline $203.5 \mathrm{MPa}$ & $>\mathrm{t}$ & $>t$ & $>t$ & $>\mathrm{t}$ & $>t$ \\
\hline
\end{tabular}

\section{References}

1. T.L. Anderson, Fracture Mechanics, 2nd Edition, 1995, CRC Press Inc., Boca Raton, Florida.

2. Newman, Stress Intensity Factors, London, Her Majesty' Stationery Office, editors. D.P. Rooke, D.J. Cartwright.

3. Shigley \& Mischke, Mechanical Engineering \& Design, 5th edition (1989), McGraw Hill Book company, U.S.A., p. 62-63

4. Ajit Roy, data to be published in NACE 1998.

5. ASM Specialty Handbook, Carbon and Alloy Steels, Edited by J.R. Davis, ASM International, Materials Park, OH, 1996, p. 349

6. Henshall and Roy, unpublished data. 


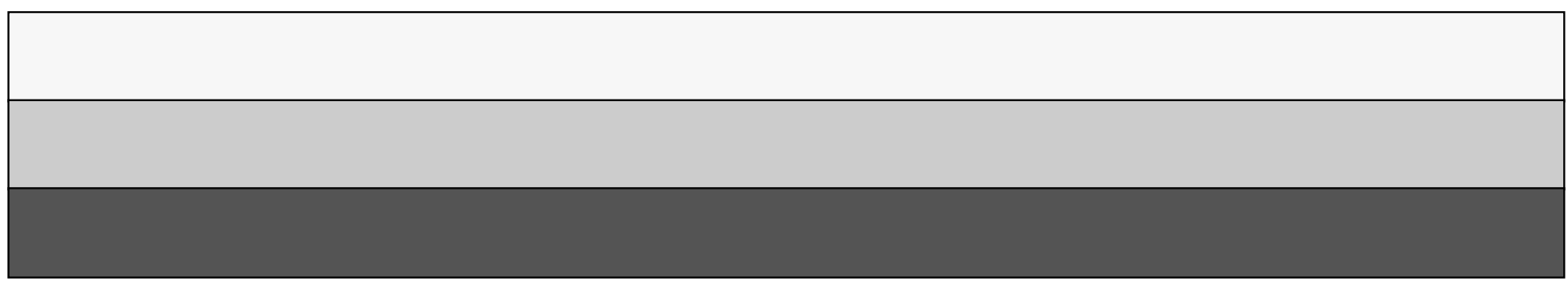

